\title{
ZBP-89-induced apoptosis is p53-independent and requires JNK
}

\author{
L Bai ${ }^{1}$, SO Yoon ${ }^{2}$, PD King ${ }^{3}$ and JL Merchant ${ }^{\star}, 1,4$ \\ ${ }^{1}$ Department of Internal Medicine, University of Michigan, Ann Arbor, Ml 48109 , \\ USA \\ 2 Department of Neuroscience, Ohio State University, Columbus, $\mathrm{OH} 43210$, \\ USA \\ ${ }^{3}$ Department of Microbiology and Immunology, University of Michigan, Ann \\ Arbor, MI 48109, USA \\ 4 Department of Molecular and Integrative Physiology, University of Michigan, \\ Ann Arbor, Ml 48109, USA \\ * Corresponding author: JL Merchant, 1150 West Medical Center Dr., MSRB I, \\ Rm. 3510, Ann Arbor, Ml 48109-0650, USA. Tel: 734647 2944; \\ Fax: 734763 4686; E-mail: merchanj@umich.edu
}

Received 22.7.03; revised 21.11.03; accepted 08.12.03; published online 13.02.04 Edited by CJ Thiele

\section{Abstract}

ZBP-89 induces apoptosis in human gastrointestinal cancer cells through a p53-independent mechanism. To understand the apoptotic pathway regulated by ZBP-89, we identified downstream signal transduction targets. Ectopic expression of ZBP-89 induced apoptosis through the mitochondrial pathway and was accompanied by activation of all three MAP kinase subfamilies: JNK1/2, ERK1/2 and P38 MAP kinase. ZBP-89-induced apoptosis was markedly enhanced by ERK inhibition with U0126. In contrast, inhibiting JNK with a JNK1specific peptide inhibitor or dominant-negative JNK2 expression abrogated ZBP-89-mediated apoptosis. The p38 inhibitor SB202190 had no effect on ZBP-89-induced cell death. Protein dephosphorylation assays revealed that ZBP- 89 activates JNK via repression of JNK dephosphorylation. Oligonucleotide microarray analyses revealed that ectopic expression of ZBP89 downregulated expression of the dual-specificity phosphatase MKP6. Overexpression of MKP6 blocked ZBP-89-induced JNK phosphorylation and PARP cleavage. In addition, ectopic expression of ZBP-89 repressed Bcl-xL and Mcl-1 expression, but had no effect on Bcl-2. Silencing ZBP-89 with small interfering RNA enhanced both $\mathrm{Bcl}-\mathrm{xL}$ and $\mathrm{Mcl}-1$ expression. Taken together, ZBP-89-mediated apoptosis occurs via a p53-independent mechanism that requires JNK activation.

Cell Death and Differentiation (2004) 11, 663-673.

doi:10.1038/sj.cdd. 4401393

Published online 13 February 2004

Keywords: siRNA; Bcl-xL; Mcl-1; Bid; dephosphorylation

Abbreviations: MAPK, mitogen-activated protein kinase; MEK, mitogen-activated protein kinase/extracellular signal-regulated kinase kinase; ERK, extracellular signal-regulated kinase; JNK, cJun N-terminal kinase; PARP, poly-(ADP ribose) polymerase; Ad, adenovirus; dnJNK2, dominant-negative c-Jun $\mathrm{N}$-terminal kinase 2; p-JNK, phosphorylated c-Jun N-terminal kinase; GFP, green fluorescence protein; siRNA, small interfering RNA; RNAi, RNA interference; JIP-1, JNK-interacting protein-1; DSP, dual-specificity phosphatase; MKP, MAP kinase phosphatase

\section{Introduction}

Programmed cell death or apoptosis is a physiologic process initiated to regulate the appropriate number of cells at epithelial surfaces during fetal development and to eliminate damaged cells. ${ }^{1}$ During neoplastic transformation, apoptosis is actively suppressed resulting in a net accumulation of cells as a result of unregulated proliferation. A variety of extracellular signals trigger apoptosis with DNA damage being the most commonly studied initiator. ${ }^{2}$ The apoptotic pathway initiated during DNA damage invariably requires an increase in p53 levels. ${ }^{3}$ Elevated p53 levels stimulate the expression of the proapoptotic protein Bax that eventually activates executioner caspases to cleave specific targets, for example, poly (ADP-ribose) polymerase (PARP), lamin A and DNA fragmentation factor (DFF). Subsequently, Bax perforates the mitochondria, and cytochrome $c$ is released into the cytoplasm. ${ }^{4}$

p53-independent pathways causing apoptosis are less well defined. They generally include proinflammatory signals and withdrawal of growth factors that in turn suppress survival factors such as Bcl-2 subsequently destabilizing mitochondrial membranes. Since most tumors contain at least one mutated p53 allele, effective treatment of these tumors by enhancing apoptosis will likely utilize pathways that exclude p53. ${ }^{5}$ Mitogen-activated protein (MAP) kinases play critical roles in both p53-dependent and -independent apoptotic pathways. ${ }^{6,7}$ The mitogenic signaling cascade (Ras-MEK1ERK) suppresses apoptosis through activation of both Raf and Akt/PKB. ${ }^{8,9}$ In contrast, the stress-activated kinases, JNK and $\mathrm{p} 38$, are signaling pathways that mediate apoptosis initiated by UV irradiation, heat shock, chemotherapy and proinflammatory cytokines. ${ }^{10-13}$ Recently, it has been shown that the phosphorylation and activation of JNK could be regulated either by activation of upstream kinases MKK4/7 or repression of upstream phosphatases. ${ }^{6,14,15}$

ZBP-89 (ZNF148, Zfp148) is a Krüppel-type zinc-finger protein that is ubiquitously expressed. ${ }^{16}$ Recent studies have revealed that ZBP-89 possesses multiple functions, including transcriptional regulation of a variety of genes, ${ }^{17}$ cell growth arrest ${ }^{18,19}$ and cell death. ${ }^{18}$ ZBP-89 expression is highest at the villus tip where apoptotic mature enterocytes are sloughed into the lumen. ${ }^{17}$ ZBP-89 stabilizes p53 by preventing its nuclear export. ${ }^{18}$ Therefore, ZBP-89 can mediate apoptosis by increasing p53 levels. More recent studies showed that Zfp148 + I- ES cells are resistant to serum starvation and continue to proliferate. ${ }^{20}$ In contrast, control ES cells respond to serum starvation by arresting cell growth. Also the haploinsufficient levels in the Zfp148+/- ES correlate with reduced phosphorylation of p53 at Ser15. Thus, reduced 
ZBP-89 protein levels render ES cells susceptible to unregulated cell growth. Using a p53 null cell line, we have shown previously that p53 is not required for ZBP-89mediated apoptosis. ${ }^{18}$ This result raised the possibility that ZBP-89 might be a key target of proapoptotic signals that do not require $\mathrm{p53}$. Here, we show that JNK activation is required for ZBP-89-induced apoptosis.

\section{Results}

\section{ZBP-89 mediated caspase activation results in PARP cleavage}

In most cases, apoptotic pathways converge by activating caspases. We have shown previously that ZBP-89 induces p53-independent apoptosis. ${ }^{18}$ To determine whether caspase activation is regulated by ZBP-89, Flag-tagged ZBP-89 was expressed in AGS cells using adenoviral vectors (Figure 1a). We found that ectopic expression of ZBP-89 promotes the cleavage of caspase-8, -9 and -3. A major target of executioner caspases is the DNA repair enzyme PARP. PARP cleavage was significantly greater in cells overexpressing ZBP-89. An increase in caspase activation contributes to either mitochondria-dependent or -independent apoptotic pathways. To establish whether ZBP-89 is sufficient to promote mitochondrial instability, cytochrome $c$ release was measured. The S-100 fraction prepared for immunoblot analysis revealed that ectopic ZBP-89 expression increases cytochrome $c$ release (Figure $1 \mathrm{~b}$ ). Collectively, evidence of

a
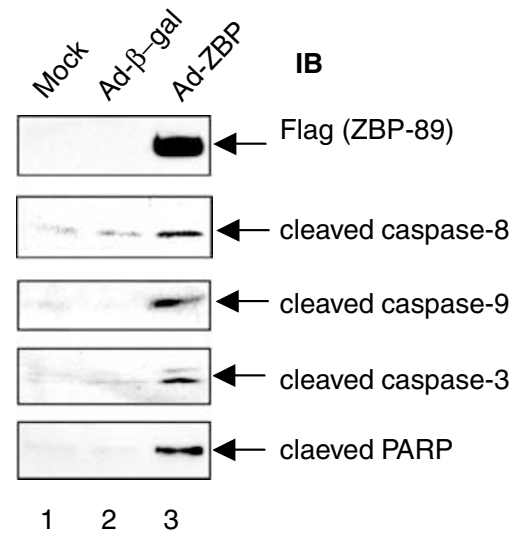

b

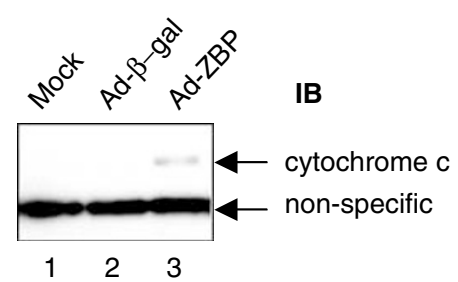

Figure 1 Ectopic expression of ZBP-89 induces the activation of apoptosis indicators. (a) AGS cells were infected with $100 \mathrm{MOI}$ of Ad-ZBP-89 or Ad- $\beta$-gal for 2 days and whole-cell extracts were prepared for immunoblots. The cleaved forms of caspase-8, -9 and -3 and PARP were detected with their specific antibodies. (b) The S-100 fraction was prepared for immunoblot analysis using a monoclonal cytochrome $c$ antibody the cleaved proteolytic enzymes, their targets and evidence of mitochondrial instability are three early molecular indicators of apoptosis. ${ }^{21-23}$ Thus, elevated ZBP-89 levels induce apoptosis through the mitochondrial pathway.

\section{ZBP-89 represses mitochondrial $\mathrm{Bcl}-2$ survival factors}

Since involvement of the mitochondrial pathway implicated changes in Bcl-2 family members, we examined whether ectopic expression of ZBP-89 involved changes in the levels of pro- or antiapoptotic Bcl-2 proteins. We found that ectopic expression did not have a significant effect on levels of the proapoptotic Bcl-2 family members, but instead effectively suppressed antiapoptotic $\mathrm{Bcl}-2$ proteins $\mathrm{Mcl}-1$ and $\mathrm{Bcl}-\mathrm{xL}$ (Figure 2a). Interestingly, there was no significant change in $\mathrm{Bcl}-2$ or Bid. To confirm that the effect on these two Bcl-2 family members occurred independently of p53, we expressed ZBP-89 in a p53 null cell line and observed the same result (Figure 2a, lanes 4-6). To further confirm that ZBP-89 specifically regulates $\mathrm{Mcl}-1$ and $\mathrm{Bcl}-\mathrm{xL}$ expression, small interfering RNA (siRNA) was used to silence ZBP-89 expression prior to examining the expression of $\mathrm{Bcl}-2$ family members (Figure 2b-d). Wild-type siRNA targeting ZBP-89 dramatically reduced ZBP-89 protein levels compared to the controls (Figure $2 \mathrm{~b}$ ). Consistent with the ability of ZBP-89 to repress $\mathrm{Bcl}-\mathrm{xL}$ and $\mathrm{Mcl}-1$ expression, reduced levels of $\mathrm{ZBP}$. 89 resulted in higher protein levels of these two $\mathrm{Bcl}-2$ family members (Figure 2c). In addition, reduced ZBP-89 levels decreased Bid and Bax expression, suggesting that ZBP-89 is required to maintain the basal levels of these two proapoptotic proteins (Figure 2c). Furthermore, co-transfection studies confirmed that ZBP-89 repressed both $\mathrm{Mcl}-1$ and $\mathrm{Bcl}-\mathrm{x}$ promoters (Figure 2d). Taken together, we concluded that elevated levels of ZBP-89 were sufficient to depress antiapoptotic $\mathrm{Bcl}-2$ family members at the levels of transcription and that this repression was p53-independent.

\section{ZBP-89 induces activation of MAP kinases}

Recently, it was been shown that the inactivation of $\mathrm{Mcl}-1$ by JNK contributes to JNK-mediated, mitochondria-dependent caspase activation in response to oxidative stress. ${ }^{24}$ Repression of $\mathrm{Bcl}-\mathrm{xL}$ and $\mathrm{Mcl}-1$ with induction of mitochondrial instability raised the possibility that ZBP-89 might also mediate $p 53$-independent apoptosis through one of the stress kinase pathways. A time course of MAP kinase activation by ZBP-89 was examined. At the indicated times following infection, cell lysates were analyzed for MAP kinase protein, phosphorylation levels and PARP cleavage. Expression of ZBP-89 after adenoviral vector infection was detectable within $8 \mathrm{~h}$ and was maximal by $24 \mathrm{~h}$ (Figure $3 \mathrm{a}$ ). The protein levels of all three MAP kinases ERK1/2, JNK1/2 and p38 did not change. ERK $1 / 2$ phosphorylation initially decreased with ZBP-89 expression and then peaked by $24 \mathrm{~h}$. The biphasic activation of ERK $1 / 2$ has been reported after prolonged growth factor treatment ${ }^{25}$ or neural activation. ${ }^{26}$ However, phosphorylation of stress MAP kinases JNK and p38 was initially low and then increased over $24 \mathrm{~h}$ following the 
a

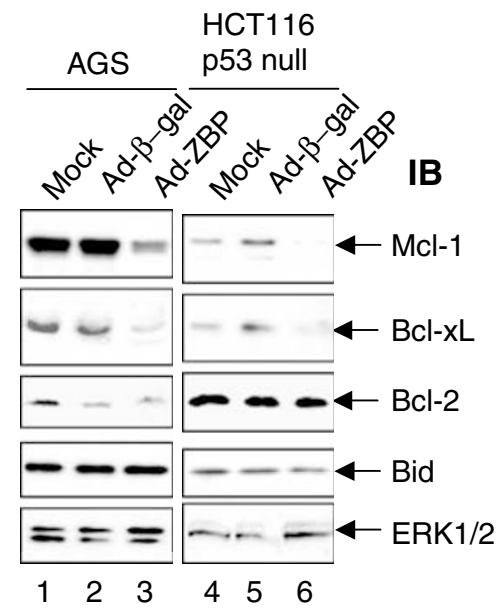

b

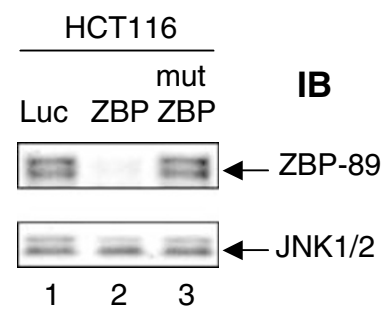

C

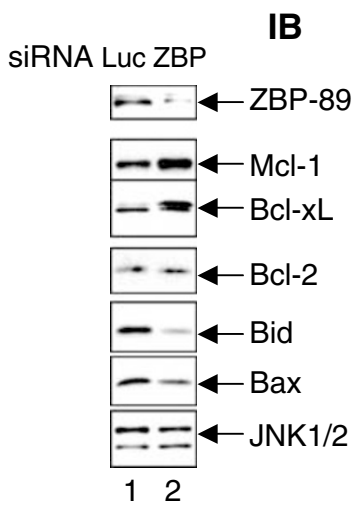

d

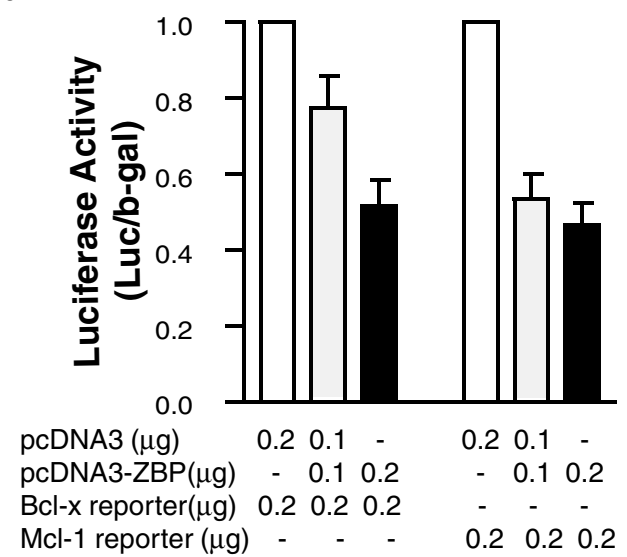

Figure 2 ZBP-89 inhibits the expression of antiapoptotic Mcl-1 and Bcl-xL. (a) AGS and HCT 116 p53 (-/-) cells were infected with $100 \mathrm{MOI}$ of Ad-ZBP-89 or Ad- $\beta$ gal. After 2 days, the cells were collected and immunoblots were performed. (b) HCT 116 cells were transfected with luciferase siRNA (Luc), ZBP-89 siRNA (ZBP) or ZBP-89 mutant siRNA (mut ZBP). The expression of ZBP-89 protein was detected with a rabbit anti-ZBP-89 antibody. (c) HCT 116 cells were transfected with siRNAs targeting luciferase (LuC) or ZBP-89 (ZBP) and the expression of Bcl-2 family members was detected by immunoblot. (d) HCT 116 cells were transiently cotransfected with Bcl-x or Mcl-1 reporters and a ZBP-89 expression vector. The relative luciferase activity was normalized to the $\beta$-galactosidase activity. The means \pm S.E.M. of three independent experiments are shown

increase in ZBP-89 protein levels. Moreover, PARP cleavage was detectable only after $24 \mathrm{~h}$. To verify that the increase in MAP kinase phosphorylation correlated with an increase in bona fide kinase activity, in vitro kinase assays were performed. Indeed, the increase in kinase phosphorylation corresponded to an increase in kinase phosphorylation of specific substrates (Figure $3 b$ ). Therefore, an increase in ZBP-89 levels correlated with increased stress MAP kinase activity, and subsequently cleavage of the downstream target of activated caspases, that is, PARP.

\section{Inhibition of ERK activation potentiates ZBP-89-induced apoptosis}

Although ZBP-89 increased the activity of all three major MAP kinases, ERK kinases are generally not associated with increased apoptosis. ${ }^{27,28}$ Therefore, to determine which kinase was actually required for ZBP-89-mediated apoptosis, specific inhibitors and dominant-negative constructs were used to block kinase activation. Cleaved caspase-3 and PARP were determined by immunoblot to assess whether the kinase inhibitors also blocked apoptosis. U0126, a specific inhibitor of MEK1/2, was used to study the contribution of MEK/MAPK (MEK: mitogen-activated protein kinase/extracellular signal-regulated kinase kinase; MAPK: mitogenactivated protein kinase) activity on ZBP-89-induced apoptosis (Figure 4a). U0126 blocked ZBP-89-induced ERK1/2 activity (Figure 4a). However, the MEK1/2 inhibitor did not block ZBP-89 induction of caspase-3 or PARP cleavage, indicating that ERK activation was not required for ZBP-89-induced apoptosis. Similarly, the p38 inhibitor SB202190 reduced p38 phosphorylation (Figure 4b) and inhibited the kinase activity (Figure 4c), but did not prevent ZBP-89-induced caspase-3 or PARP cleavage (Figure 4b).

To further document that inhibition of ERK $1 / 2$ or p38 kinases was not required for ZBP-89-induced apoptosis, AGS 
a

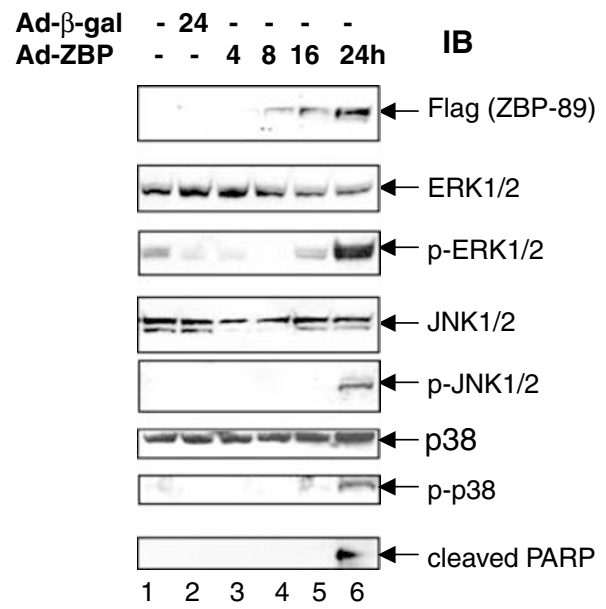

b

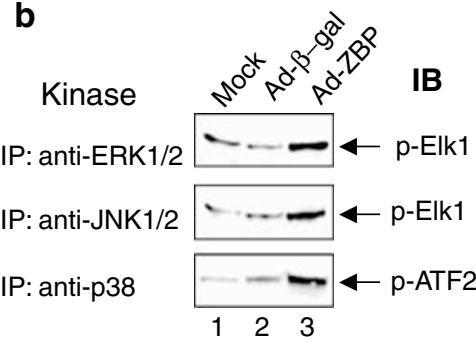

Figure 3 Ectopic expression of ZBP-89 induces the activation of ERK, JNK and p38 MAP kinases. (a) AGS cells were infected with $100 \mathrm{MOI}$ of Ad-ZBP-89 or Ad$\beta$-gal. At the indicated time points, cells were collected and lysed for immunoblot analysis. The levels of phosphorylated ERK ( $p$-ERK), phosphorylated JNK ( $p$ JNK) and phosphorylated p38 (p-p38) were detected using the respective phospho-specific antibodies. Total ERK $1 / 2$, JNK1/2 or p38 were also detected as a control for protein loading. (b) Whole-cell extracts from AGS cells were immunoprecipitated with antibody against phosphorylated ERK $1 / 2$, JNK1/2 or p38. The in vitro kinase assays were performed as described in Materials and Methods

cells were infected with adenoviral vectors for $48 \mathrm{~h}$ in the presence of U0126 or SB202190 and then processed for flow cytometry (Figure 4d). Treatment of the cells with Ad-ZBP-89 alone increased the percent of cells in sub-G1 as an indicator of apoptosis. Treatment with U0126 alone induced the same level of apoptosis as observed with ZBP-89. Further, ZBP-89 overexpression coupled with ERK1/2 inhibition enhanced the level of apoptosis two-fold. In contrast, treatment with the p38 kinase inhibitor had no effect on the basal level of apoptosis in AGS cells nor was ZBP-89-induced apoptosis further enhanced (Figure 4d). Collectively, these results demonstrate that inhibition of the ERK1/2 signaling pathway potentiates ZBP-89-induced apoptosis and is consistent with ERK1/2 having an antiapoptotic effect. ${ }^{9}$ Although the kinetics of both stress kinases p38 and JNK best correlated with ectopic ZBP89 expression and induction of apoptosis, p38 activation was not required for ZBP-89-induced apoptosis. Despite p38 kinases being required in some cells for p53-independent activation of apoptosis, ${ }^{29,30}$ this pathway was clearly dispensable for ZBP-89-mediated apoptosis.

\section{ZBP-89-induced apoptosis requires JNK signaling}

To assess the role of JNK signaling in ZBP-89-induced apoptosis, a JNK1-specific peptide inhibitor was used to block ZBP-89-induced activation of the kinase (Figure 5a). Pretreatment of AGS cells with the JNK inhibitor attenuated JNK phosphorylation of its downstream target c-Jun and reduced cleavage of procaspase-3 and PARP. Moreover, there was a significant decrease in ZBP-89-induced apoptosis determined by flow cytometry with the JNK inhibitor (Figure 5b). A dominant-negative JNK2 (dnJNK2) expression vector was also used to inhibit JNK phosphorylation (Figure $5 \mathrm{c}$ ). The expression of the dnJNK2 vector decreased JNK activity and correlated with a decrease in the amount of cleaved caspase3 and PARP generated. The effect of dnJNK was specific since ERK1/2 phosphorylation was not affected (Figure $5 c$ ). Moreover, dnJNK2 blocked cytochrome $c$ release (Figure $5 \mathrm{~d}$ ) and the increase in the number of cells in sub-G1 expected with ectopic expression of ZBP-89 (Figure 5e). Apoptotic pathways requiring JNK signaling have been linked previously to the release of cytochrome $c$ from mitochondria. ${ }^{31,32}$ Therefore, JNK activation is required for ZBP-89-mediated apoptosis.

To confirm whether ZBP-89-induced JNK activation was p53-independent, both AGS, HCT116 p53 $(+/+)$ and HCT116 p53 (-/-), cells were infected. Indeed we found that ZBP-89-mediated JNK activation is independent of p53 status (Figure 6).

\section{ZBP-89 represses JNK dephosphorylation}

Delayed JNK activation during ZBP-89 overexpression (see Figure 3) suggested that the effect of ZBP-89 on JNK was indirect. To test whether kinases that phosphorylate JNK were activated by ZBP-89 overexpression, MKK4/7 kinase assays were performed (Figure 7a). IL-1 $\beta$ activates JNK mainly through MKK7, whereas, anisomycin activates JNK primarily through MKK4 (Figure 7a). However, ectopic expression of ZBP-89 did not activate MKK4 or MKK7 (Figure 7a). This suggested that MKK4/MKK7 activation did not mediate the activation of JNK by ZBP-89. Balanced phosphorylation/ dephosphorylation regulates JNK activity. Thus, ZBP-89mediated JNK phosphorylation might be due to decreased dephosphorylation. To determine whether ZBP-89 had any effect on JNK-dependent phosphatase activity, dephosphorylation of JNK was assayed during ectopic expression of ZBP-89. Both IL-1 $\beta$ and anisomycin stimulate JNK1/2 phosphorylation, and ATP depletion rapidly dephosphorylates JNK $1 / 2^{33}$ (Figure 7b). At 10 min after ATP depletion, IL-1 $\beta$ induced JNK1 phosphorylation decreased by $\sim 85 \%$ and anisomycin-induced JNK1 phosphorylation decreased by $\sim 70 \%$ (Figure 7c). In contrast to the dephosphorylation of JNK1/2 after IL-1 $\beta$ and anisomycin treatment, dephosphorylation of ZBP-89-induced JNK1 phosphorylation was significantly delayed (Figure $7 \mathrm{~b}$ ) and decreased by only $\sim 35 \%$ (Figure 7c). Thus, we concluded that ZBP-89 promotes JNK phosphorylation by reducing its dephosphorylation.

As ectopic expression of ZBP-89 activates all three MAP kinases, we predicted that ZBP-89 controls a common upstream regulator of these MAP kinases. Recently, it has 
a

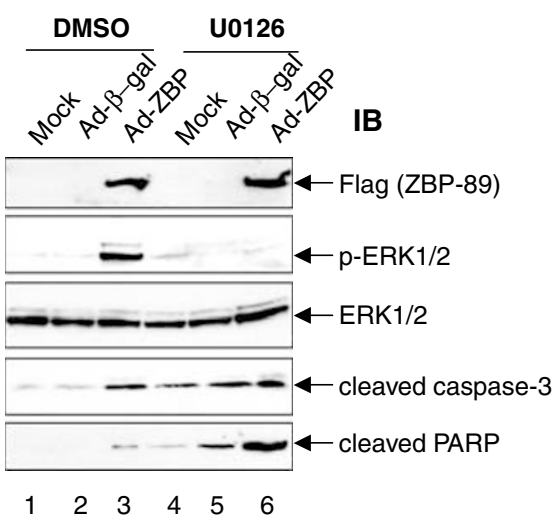

C

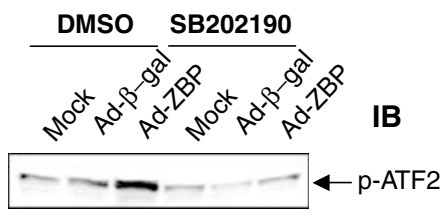

$\begin{array}{llllll}1 & 2 & 3 & 4 & 5 & 6\end{array}$ b

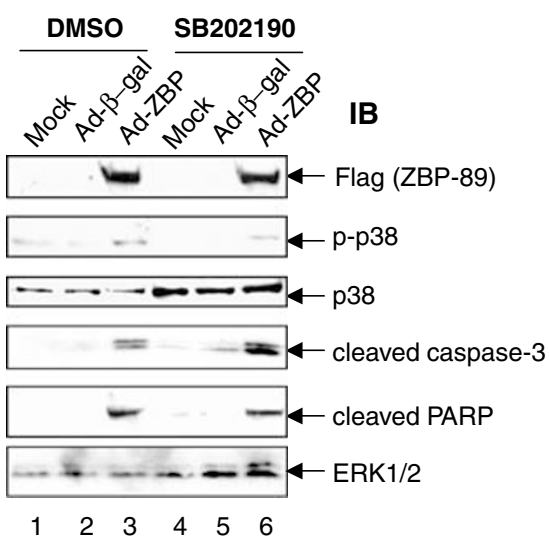

d

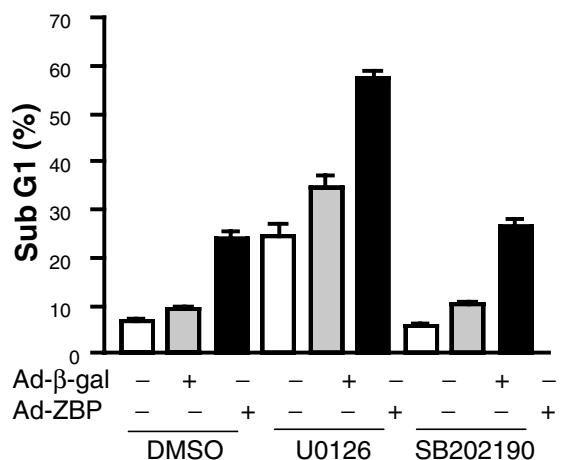

Figure 4 Effect of MEK1/2 and p38 inhibitors on ZBP-89-induced apoptosis. (a) AGS cells were pretreated with $10 \mathrm{mM}$ U0126 for $30 \mathrm{~min}$ and then infected with $100 \mathrm{MOI}$ of Ad-ZBP-89 or Ad- $\beta$-gal. After 2 days, the cells were collected and immunoblot analysis was performed to detect the phosphorylated ERK $1 / 2$, cleaved caspase-3 and cleaved PARP. (b) AGS cells were pre treated with $10 \mathrm{mM}$ of SB202190 for 30 min and then incubated with $100 \mathrm{MOl}$ of Ad-ZBP-89 or Ad- $\beta$-gal prior to immunoblots analysis. (c) Whole-cell extracts from AGS cells were immunoprecipitated with antibody against phosphorylated p38 for the in vitro p38 kinase assays. (d) Parallel sets of cells were fixed and flow cytometry was performed to quantify the number of apoptotic cells. The means \pm S.E.M. of three experiments performed in triplicate are shown

been reported that the JNK-interacting protein-1(JIP-1) reduces JNK activation by binding to a dual-specificity phosphatase MAPK phosphatase 7 (MKP7). ${ }^{34}$ Thus, the effect of ZBP-89 on JIP-1 expression was examined (Figure 8a). Ectopic expression of ZBP-89 had no significant effect on JIP-1 expression (Figure 8a). Thus, ZBP-89 suppression of JNK dephosphorylation appears to be independent of JIP-1. To further identify other candidates regulated by ZBP-89 that in turn could modulate JNK dephosphorylation, microarray analysis was performed (Table 1). Silencing ZBP-89 gene expression with siRNA upregulated MKPL (MAP Kinase Phosphatse 1 Like; MKP6) expression 2-fold (Table 1). MKPL (MKP6) is a dual-specific MAPK phosphatase that dephosphorylates JNKs as well as ERKs and p38 MAPKs. ${ }^{35}$ RNase protection confirmed that reducing ZBP-89 mRNA levels with ZBP-89-specific siRNA upregulates MKP6, while overexpression of ZBP-89 slightly downregulated the expression of this phosphatase (Figure 8b). Considering the kinetics of protein kinase cascades, minor changes in the activity of upstream MKP6 would cause a significant change in the phosphorylation status of the downstream JNK. Therefore, we concluded that ZBP-89 activates JNK through repression of its depho- sphorylation and that ZBP-89 repression of MKP6 is a possible mechanism. To further support the hypothesis that MKPL (MKP6) is the phosphatase repressed by ZBP-89 during apoptosis, we overexpressed MKP6 (Figure 8c). As expected, overexpression of ZBP-89 increased JNK phosphorylation and triggered apoptosis (PARP cleavage) (Figure 8c, lanes 1-3). When MKP6 was overexpressed in the presence of elevated levels of ZBP-89, JNK phosphorylation decreased and PARP cleavage was reduced (Figure 8c, lanes 4-6). Thus, we concluded that ZBP-89 can suppress MKP6 subsequently increasing JNK phosphorylation that in turn promotes apoptosis.

\section{Discussion}

ZBP-89 is a potent inducer of apoptosis in gastrointestinal cancer cells. ${ }^{18}$ In this study, we found that all three MAP kinases can be activated by ZBP-89. However, only the JNK stress-related kinase was required for ZBP-89-mediated apoptosis. Activation of the JNK pathway is a common mechanism resulting in apoptotic cell death. ${ }^{13,36-39}$ However, the importance of this activation varies according to the type of 


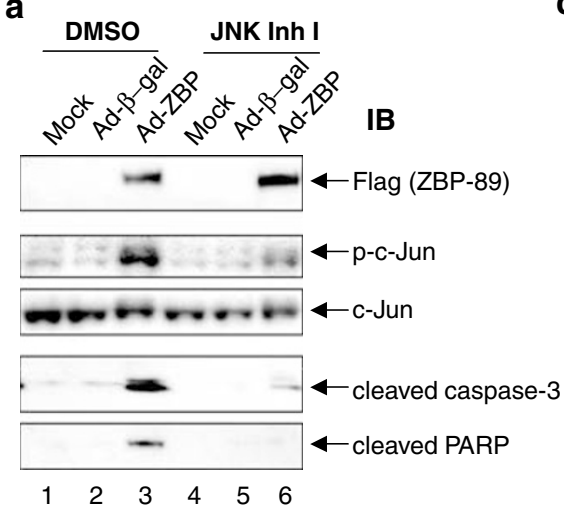

b

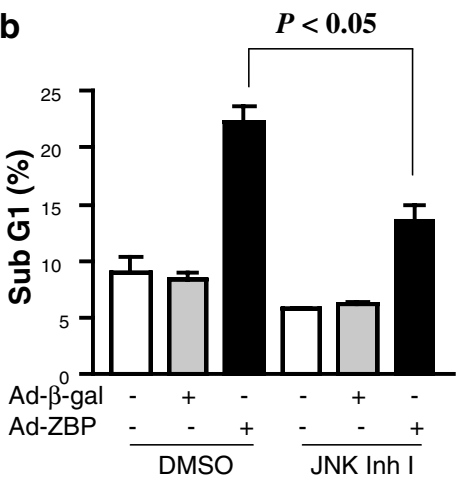

C

Ad-GFP Ad-dnJNK

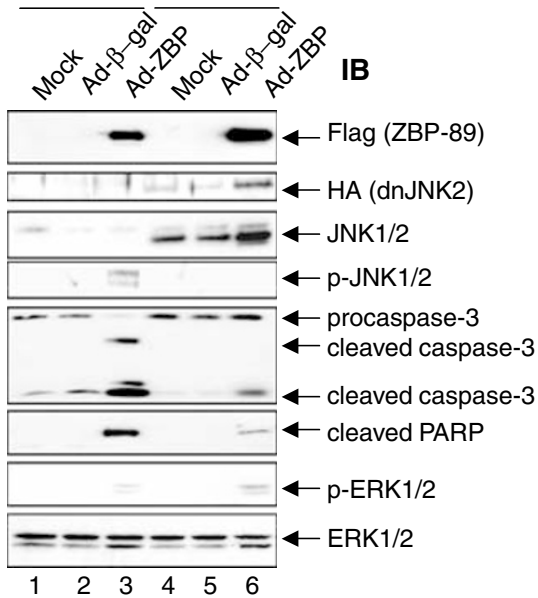

d Ad-GFP Ad-dnJNK

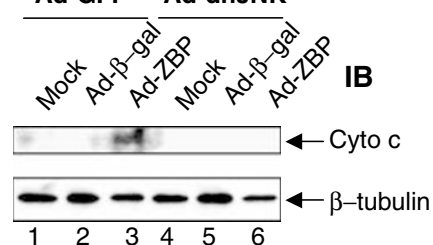

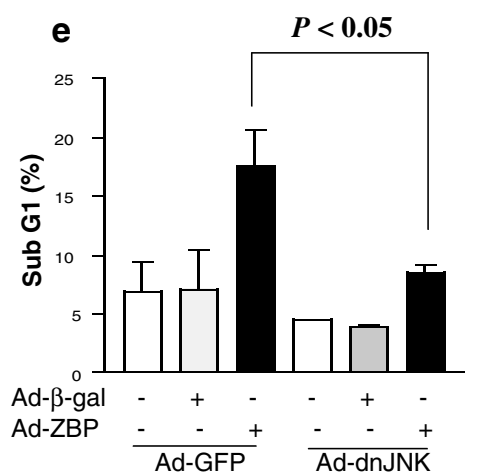

Figure 5 Interfering with JNK signaling abrogates ZBP-89-induced apoptosis. (a) AGS cells were pretreated with $10 \mathrm{mM} \mathrm{JNK}$ inhibitor I for $2 \mathrm{~h}$ and then infected with $100 \mathrm{MOI}$ of Ad-ZBP-89 or Ad- $\beta$-gal. After 2 days, the cells were collected and immunoblot analysis was performed to detect phospho-c-Jun, cleaved caspase- 3 and cleaved PARP. (b) Parallel sets of cells were fixed and flow cytometry was performed to quantify the number of apoptotic cells. The means \pm S.E.M. of three experiments performed in triplicate are shown. (c) AGS cells were infected with $10 \mathrm{MOI}$ of Ad-dnJNK2 for $8 \mathrm{~h}$ and then infected with $100 \mathrm{MOI}$ of Ad-ZBP- 89 or Ad- $\beta$-gal. After $48 \mathrm{~h}$, the cells were collected and immunoblot analysis was performed. (d) AGS cells were treated as in (c). The S-100 fraction was prepared for immunoblot analysis. Cytochrome $c$ was detected with a monoclonal cytochrome $c$ antibody. (e) Parallel sets of cells from (c) were fixed for flow cytometry to quantify the number of apoptotic cells. The means \pm S.E.M. of three experiments performed in triplicate are shown

stimulus. The JNK pathway is required for apoptosis induced by proinflammatory cytokines, growth factor withdrawal, heat shock, radiation and ceramide. ${ }^{13,36-38}$ In contrast, JNK may not be essential for receptor-mediated apoptosis (e.g. Fasand tumor necrosis factor-mediated apoptosis). ${ }^{40,41}$

The mechanism by which JNK becomes activated in response to apoptotic signals is not completely understood. JNK activity is regulated by specific kinases (e.g. ASK-1, MKK $4,7)$ and phosphatases. ${ }^{42,43}$ Studies on BRCA1 have revealed that this tumor suppressor protein activates JNK by upregulating GADD45 and MKK4/7. ${ }^{44}$ The GADD family of proteins was identified as gene products overexpressed during DNA damage. ${ }^{45}$ While there is no direct evidence that ZBP-89 is activated during DNA damage, studies by Hasegawa et al. $^{46}$ have identified a GADD-like protein by two-hybrid screen using ZBP-89 as bait. Instead, ZBP-89 regulates JNK phosphorylation and activity by suppressing its dephosphorylation through the dual-specificity phosphatase MKPL (MKP6). Whether the effect of ZBP-89 on the phosphatase promoter or protein is direct or indirect is not known. Regulation of JNK activity through inhibition of its dephosphorylation is not well understood. However, the ability 


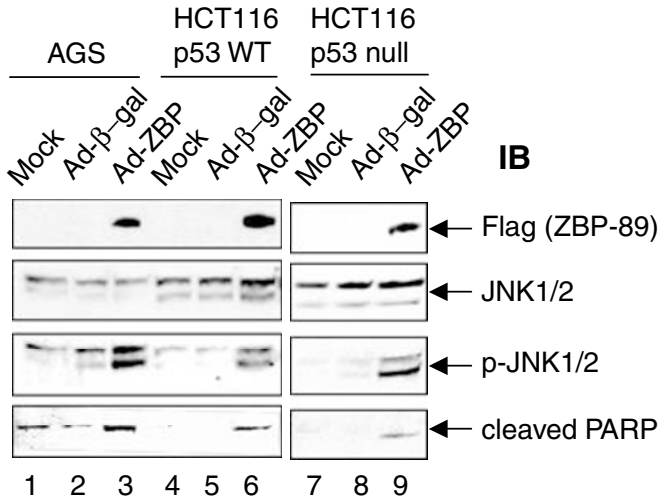

Figure 6 ZBP-89 induced JNK activation is p53-independent. AGS, HCT 116 p53 $(+/+)$ and HCT 116 p53 $(-/-)$ cells were infected with $100 \mathrm{MOI}$ of AdZBP- 89 or Ad- $\beta$-gal. After 2 days, the cells were collected and immunoblots were performed to detect phosphorylated-JNK1/2 and cleaved PARP

of ZBP-89 to suppress the dual-specificity phosphatase MKPL (MKP6) would also explain how ZBP-89 increases the phosphorylation status of p38 and ERK1/2.

Using the MEK1/2-specific inhibitor U0126, we found that activation of the ERK pathway is antiapoptotic since the inhibitor enhanced ZBP-89-induced apoptosis. Thus, ZBP-89 activation of the ERKs was not sufficient to override initiation of the proapoptotic cascade. ERK activation is usually considered a proproliferative, prosurvival signal. ${ }^{47,48}$ However, recent studies have shown that ERK activation may also result in cell cycle arrest, emphasizing that the responses may differ depending on the cell type and nature of the extracellular signal and its duration. ${ }^{49-52}$ In addition, the timing and actual amounts of ZBP-89 protein generated might modulate which downstream kinase is activated. Similar to our findings with ZBP-89, overexpression of BRCA1 in MCF-7 breast cancer cells also activates both JNK (proapoptotic) and ERK (antiapoptotic) pathways, and MEK1/2 inhibition enhances BRCA1-induced apoptosis. ${ }^{53}$ In fact, recent microarray analysis of MCF-7 cell line have revealed that ZBP-89 increases two-fold with overexpression of BRCA-1, suggesting that ZBP-89 lies downstream of this tumor suppressor gene product. ${ }^{3}$ Thus, there may be synergy between BRCA1 and ZBP-89 apoptotic pathways.

The tumor suppressor $\mathrm{p} 53$ is essential for genotoxic stressinduced apoptosis. ${ }^{54,55}$ p53 may promote apoptosis by upregulating Bax gene expression, ${ }^{56}$ a Bcl-2 family member that opposes Bcl-2 survival factors, Bcl-2, Bcl-xL, Mcl-1. ${ }^{57}$ Although ZBP-89 stabilizes p53 protein, ${ }^{18}$ an increase in Bax was not a prominent finding in our study. These data support our previous observation that ZBP-89-induced apoptosis is p53-independent. ${ }^{18}$ An alternative mechanism considered was repression of Bcl-2 family members $\mathrm{Mcl}-1$ and $\mathrm{Bcl}-\mathrm{xL}$ involved in survival, since these genes were strongly repressed by ectopic ZBP-89. Bcl-2 survival proteins are known to be inhibited by JNK. ${ }^{58-61}$ In the case of Bcl-2 and Mcl-1, JNK inactivates these survival factors by direct phosphorylation. $^{24,62}$ However, ZBP-89 expression had no effect on Bcl-2. In contrast, we found that $\mathrm{Bcl}-2$ family members, $\mathrm{Bcl}-\mathrm{xL}$ and $\mathrm{Mcl}-1$, were the primary $\mathrm{Bcl}-2$ survival factors targeted by ZBP-89. ZBP-89 strongly suppressed
$\mathrm{Bcl}-\mathrm{xL}$ and $\mathrm{Mcl}-1$ gene expression and protein levels. The mechanism of $\mathrm{Mcl}-1$ suppression of apoptosis is known to be p53-independent. ${ }^{63-65}$ Furthermore, reduced $\mathrm{Bcl}-\mathrm{xL}$ levels promote p53-independent apoptosis. ${ }^{66}$ Taken together, ZBP89 represses $\mathrm{Mcl}-1$ and $\mathrm{Bcl}-\mathrm{xL}$ by two mechanisms that work in concert: first, by inhibiting the gene expression of these survival factors and, second, by increasing JNK activity that in turn can inhibit these survival factors by phosphorylation.

\section{Materials and Methods}

\section{Antibodies and chemicals}

Rabbit ZBP-89 antibody has been previously described. ${ }^{16}$ Monoclonal antibodies against phospho-ERK1/2, phospho-p38, phospho-JNK1/2, phospho-Elk1, phospho-ATF2 and caspase-8, and polyclonal antibodies against ERK1/2, p38, JNK, c-Jun, phospho-c-Jun, cleaved PARP, caspase-3, cleaved caspase-3, caspase- 9 , cleaved caspase- 9 and Bid were obtained from Cell Signaling (Beverly, MA, USA). The monoclonal Flag M2 antibody was purchased from Sigma (St Louis, MO, USA). Rabbit polyclonal antibodies against Mcl-1, Bcl-xL, MEK-4, MEK-7, Sp1 and Sp3 and JIP-1 monoclonal antibody were obtained from Santa Cruz Biotechnology (Santa Cruz, CA, USA). Rabbit polyclonal anti-Bax and anti-Bcl-2 were obtained from Oncogene (San Diego, CA, USA). U0126 (MEK1/2 inhibitor), SB202190 (p38 inhibitor), the JNK peptide inhibitor I, $\mathrm{IL}-1 \beta$ and anisomycin were purchased from Calbiochem (San Diego, CA, USA). Rotenone and 2-deoxyglucose were from Sigma (St Louis, MO, USA).

\section{Cell culture}

The AGS (human gastric adenocarcinoma cell line) was purchased from ATCC (Manassas, VA, USA) and cultured in Dulbecco's modified Eagle's medium (DMEM) with 10\% fetal bovine serum (FBS). HCT116 p53 $(+/+)$ and p53 $(-/-)$ cells were gifts from Dr. Bert Vogelstein (John Hopkins University) and were cultured in McCoy's $5 \mathrm{~A}$ medium with $10 \%$ FBS. In some experiments, the cells were treated with SB203580 or U0126 for $30 \mathrm{~min}$, or JNK peptide inhibitor I for $2 \mathrm{~h}$ prior to adding adenoviruses (Ads). The inhibitors were present during the incubation period.

\section{Adenovirus and retroviruses}

Replication-deficient recombinant Ad-ZBP-89 expressing full-length Flagtagged rat ZBP- 89 CDNA and control Ad- $\beta$-galactosidase Ads have been previously described. ${ }^{67}$ Ad-GFP (GFP: green fluorescence protein) and Ad-dnJNK2 (encoding an HA-tagged dominant-negative JNK2 mutant) $\mathrm{Ads}^{68}$ and the Flag-MKP6-expressing retroviral vector have been described before. ${ }^{35}$

\section{Flow cytometry}

Cells were plated onto six-well plates and infected with recombinant adenoviral vectors as described above. After $48 \mathrm{~h}$, the cells were collected and processed for flow cytometry as described previously. ${ }^{18}$

\section{Immunoblot analyses}

Whole-cell extracts were prepared in lysis buffer $(20 \mathrm{mM}$ Tris- $\mathrm{HCl}, \mathrm{pH} 7.4$, $0.2 \%$ Nonidet P-40, $0.5 \mathrm{mM}$ EDTA, $1 \mathrm{mM}$ dithiothreitol (DTT)) and analyzed by immunoblotting. ${ }^{67}$ 
a

MKK4
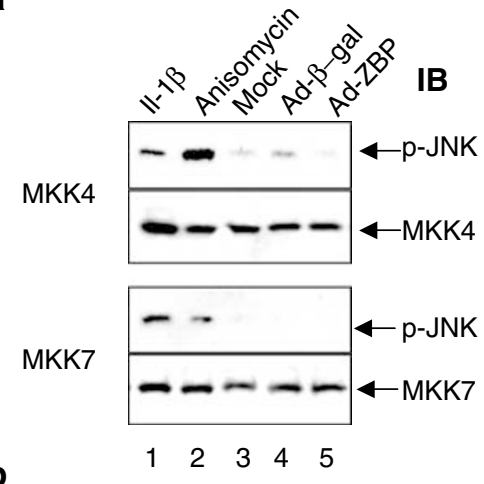

b

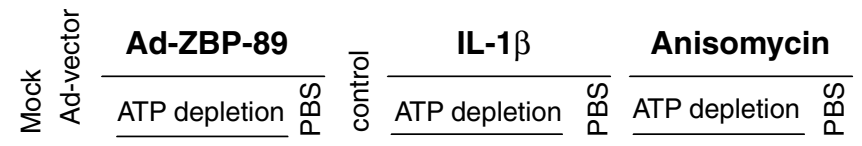

Time (min)

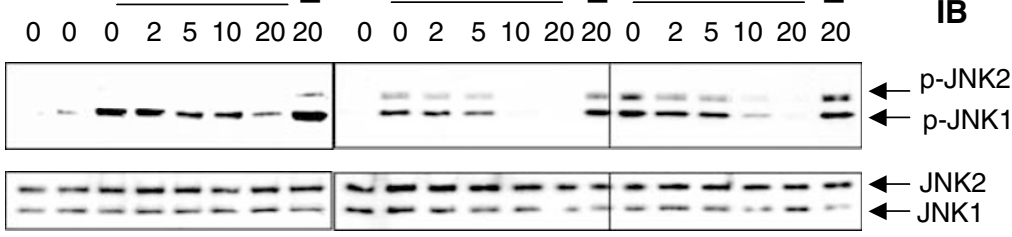

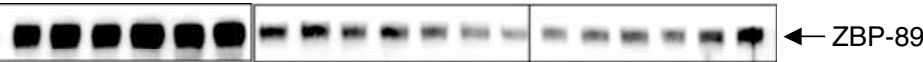

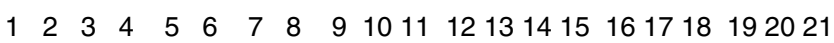

C

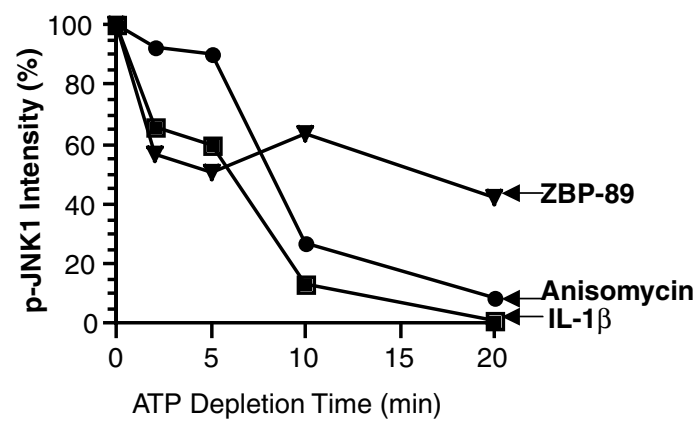

Figure 7 ZBP-89 reduced JNK dephosphorylation. (a) HCT 116 cells were infected with $100 \mathrm{MOl}$ of Ad-ZBP-89 or Ad- $\beta$-gal for 2 days or treated with $15 \mathrm{ng} / \mathrm{ml}$ IL-1 $\beta$ or $50 \mu \mathrm{M}$ anisomycin for $15 \mathrm{~min}$. Whole-cell extracts were immunoprecipitated with antibody against MKK4 or MKK7. The in vitro kinase assays were performed as described in Materials and Methods. (b) HCT 116 cells were first infected with $100 \mathrm{MOI}$ of Ad-ZBP-89 or Ad- $\beta$-gal for $36 \mathrm{~h}$ or treated with $15 \mathrm{ng} / \mathrm{ml}$ IL- $1 \beta$ or $50 \mu \mathrm{M}$ anisomycin for $15 \mathrm{~min}$, and then 2-deoxyglucose and rotenone were added to deplete ATP for up to $20 \mathrm{~min}$. Cellular extracts were prepared and the levels of phosphoJNK1/2 were detected with immunoblots. (c) Quantitation of phospho-JNK1 levels described in (b). Values are the means of two independent experiments

\section{Protein kinase activity assay}

MAP kinase activity assays were performed using the MAP kinase assay kit (Cell Signaling, Inc.). Briefly, the cells were collected and lysed on ice in a buffer containing $20 \mathrm{mM}$ Tris (pH 7.5), $150 \mathrm{mM} \mathrm{NaCl}, 1 \mathrm{mM}$ EDTA, $1 \mathrm{mM}$ EGTA, $1 \%$ Triton $\mathrm{X}-100,2.5 \mathrm{mM}$ sodium pyrophosphate, $1 \mathrm{mM} \beta$ glycerolphosphate, $1 \mathrm{mM} \mathrm{Na}_{3} \mathrm{VO}_{4}$ and $1 \mathrm{mM}$ phenylmethylsulfonyl fluoride (PMSF). The JNK1/2, ERK1/2 or p38 MAP kinases were immunoprecipitated during gentle agitation overnight at $4^{\circ} \mathrm{C}$ using a monoclonal antibody for phosphorylated JNK1/2, ERK1/2 or p38 immobilized on sepharose beads. The immunoprecipitated complex was collected, washed and then incubated for $30 \mathrm{~min}$ at $30^{\circ} \mathrm{C}$ in kinase buffer containing $25 \mathrm{mM}$ Tris (pH 7.5), $5 \mathrm{mM} \beta$-glycerolphosphate, $2 \mathrm{mM}$ DTT, $0.1 \mathrm{mM}$ $\mathrm{Na}_{3} \mathrm{VO}_{4}$ and $10 \mathrm{mM} \mathrm{MgCl}$, plus $2 \mu \mathrm{g} / \mu$ l of GST-Elk1 or GST-ATF2 fusion protein as the substrate. Phosphorylation of the substrate was detected by resolving the kinase reaction and then immunoblotting, using an antibody specific for phosphorylated Elk1 or ATF2.

To measure MKK4 and MKK7 activities, MKK4 and MKK7 were first immunoprecipitated using their respective antibodies followed by incubation with GST-JNK2 (Stressgen) in the kinase buffer described above. Phosphorylation of GST-JNK2 was detected by immunoblotting with a monoclonal antibody specific for phosphorylated JNK.

\section{Analysis of JNK dephosphorylation}

HCT 116 cells were infected with either Ad vector or Ad-ZBP-89 for $36 \mathrm{~h}$, or treated with IL-1 $\beta(20 \mathrm{ng} / \mathrm{ml})$ and anisomycin $(50 \mu \mathrm{M})$ for $15 \mathrm{~min}$. Cells 
were washed first with warmed PBS twice, followed by incubating with PBS containing $20 \mathrm{mM}$ 2-deoxyglucose and $5 \mu \mathrm{M}$ rotenone for the indicated time points. Immunoblots were performed as described above to detect the phosphorylation status of JNK1/2.

\section{Subcellular fractionation (S-100) for analysis of cytochrome $c$ release}

Subcellular fractionation was performed according to the method of Liu et al. ${ }^{69}$ Harvested cells were washed twice with ice-cold PBS and then resuspended in five volumes of ice-cold buffer $A(20 \mathrm{mM}$ Hepes $(\mathrm{pH} 7.5)$, $10 \mathrm{mM} \mathrm{KCl}, 1.5 \mathrm{mM} \mathrm{MgCl}, 1 \mathrm{mM}$ sodium EDTA, $1 \mathrm{mM}$ sodium EGTA, $1 \mathrm{mM}$ DTT and $0.1 \mathrm{mM}$ PMSF) supplemented with protease inhibitors $(\alpha$ Complete, Roche, Indianapolis, IN, USA). After being placed on ice for $15 \mathrm{~min}$, the cells were disrupted by douncing 15 times followed by centrifugation at $1000 \times g$ for $10 \mathrm{~min}$ at $4^{\circ} \mathrm{C}$. The supernatant was further centrifuged at $100000 \times g$ for $1 \mathrm{~h}$. The resulting supernatant $(\mathrm{S}-100$
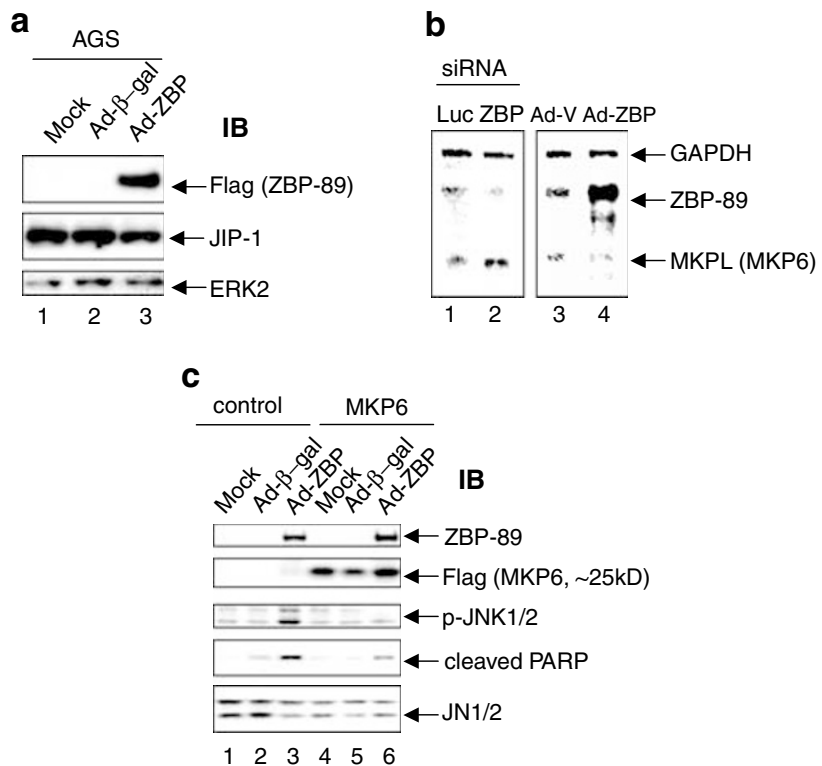

Figure 8 ZBP-89 downregulates MKP6 expression. (a) AGS cells were infected with $100 \mathrm{MOI}$ of Ad-ZBP-89 or Ad- $\beta$-gal. After 2 days, the cells were collected and immunoblots were performed to detect JIP-1 protein levels. (b) HCT 116 cells were either infected with Ad vector or Ad-ZBP-89 for 2 days or transfected with siRNA targeting luciferase (Luc) or ZBP-89 (ZBP) for 3 days. Total RNAs were prepared for RNase protection assays to detect the amount of MKPL, ZBP-89 and GAPDH (control) mRNA as described in the Materials and Methods. (c) HCT 116 cells were infected with LNCX control retrovirus or FlagMKP6 retroviruses and selected with G418 at $1 \mathrm{mg} / \mathrm{ml}$ for 3 days. The G418resistant cells were then infected with $50 \mathrm{MOI}$ of Ad-ZBP-89 or Ad- $\beta$-gal for 2 days. The cells were collected and immunoblot analysis was performed fraction) was processed for immunoblotting using cytochrome $c$ antibody (Oncogene).

\section{RNA interference}

RNA interference (RNAi) experiments with siRNA were carried out using the method of Elbashir et al. ${ }^{70}$ The region of ZBP-89 cDNA targeted for siRNA was + 142 5'AAGATCGAAGTATGCCTCACCTT3'. A mutated ZBP-89 siRNA (5'AAGATCGAACGTGTCCTCACCTT3') and an siRNA targeted to pGL2 luciferase cDNA (5'AACGTACGCGGAATACTTCGATT3') were used as controls. Synthetic 21-mer sense and antisense oligonucleotides (Xeragon, Germantown, MD, USA) were annealed as instructed before use. siRNAs were transfected into cells using Oligofectamine (Invitrogen).

\section{RNase protection assay}

Total RNA was isolated from cells using TRIZOL reagent (Invitrogen). The pTRI-GAPDH-human antisense control template (BD Pharmingen, San Diego, CA, USA) and a ZBP-89 template were used to generate riboprobes using MAXIscript In vitro Transcription Kit (Ambion, Austin, TX, USA). To generate an MKPL riboprobe template, $170 \mathrm{bp}$ of MKPL cDNA was amplified using the following PCR primers: forward 5'TGAGCTCCAGAGGTCACAGC3' and backward 5'CAATGCAGGTGATGCCACGAG3'. The PCR fragment was cloned into the PCR2.1 vector (Invitrogen) and the orientation was verified by sequencing. BstXI was used to linearize PCR-MKPL to produce the MKPL riboprobe template. The RNase protection assay was performed as described previously. ${ }^{67}$

\section{Oligonucleotide microarray}

Total RNA was isolated using TRIZOL reagent (Invitrogen). The Affymetrix HG-U133A oligonucleotide chip representing about 33000 human genes was used for the hybridization. The cRNA probe, labeling, hybridization and data analysis were performed by the University of Michigan NIDDK Biotechnology Center. A detailed protocol for the sample preparation and microarray processing is available from Affymetrix, Inc. (Santa Clara, CA, USA).

\section{Acknowledgements}

The work was supported by Public Health Service NIH Grant DK 55732 to JLM. We thank the University of Michigan Cancer Center (5P30 CA46592) for use of the flow cytometry and vector cores. We also acknowledge use of the Michigan NIDDK Biotechnology Center (U24 DK58771). We thank Dr. Bert Vogelstein (Johns Hopkins University) for providing the HCT 116 p53 wild-type and null cell lines.

Table 1 Silencing ZBP-89 upregulates MKP-L expression in HCT 116 cells

\begin{tabular}{|c|c|c|c|c|c|c|c|c|}
\hline \multirow[t]{2}{*}{ Gene } & \multicolumn{3}{|c|}{ Control siRNA } & \multicolumn{3}{|c|}{ ZBP-89 siRNA } & \multirow[t]{2}{*}{ Fold change } & \multirow[t]{2}{*}{ P-value } \\
\hline & \#1 & \#2 & \#3 & \#1 & \#2 & \#3 & & \\
\hline $\begin{array}{l}\text { MKP-L (MKP6) } \\
\text { ZNF148 (ZBP-89) }\end{array}$ & $\begin{array}{r}2238 \\
447\end{array}$ & $\begin{array}{r}2695 \\
480\end{array}$ & $\begin{array}{r}2181 \\
437\end{array}$ & $\begin{array}{r}4259 \\
262\end{array}$ & $\begin{array}{r}4519 \\
226\end{array}$ & $\begin{array}{r}3619 \\
247\end{array}$ & $\begin{array}{l}1.74 \\
0.54\end{array}$ & $\begin{array}{l}0.004 \\
0.00023\end{array}$ \\
\hline
\end{tabular}

HCT 116 cells were transfected with siRNAs targeting luciferase (control) or ZBP-89. Total RNA was isolated for microarray analysis. Results are from hybridization of RNA samples to Affymetrix chip HG-U133A from three independent siRNA transfection experiments. MKPL, MAP Kinase Phosphatse 1 Like 


\section{References}

1. Hatano $E$, Bradham CA, Stark A, limuro $Y$, Lemasters JJ and Brenner DA (2000) The mitochondrial permeability transition augments Fas-induced apoptosis in mouse hepatocytes. J. Biol. Chem. 275: 11814-11823

2. Blagosklonny MV (2002) P53: an ubiquitous target of anticancer drugs. Int. J. Cancer 98: 161-166

3. Welcsh PL, Lee MK, Gonzalez-Hernandez RM, Black DJ, Mahadevappa M, Swisher EM, Warrington JA and King MC (2002) BRCA1 transcriptionally regulates genes involved in breast tumorigenesis. Proc. Natl. Acad. Sci. USA 99: 7560-7565

4. Schuler M and Green DR (2001) Mechanisms of p53-dependent apoptosis. Biochem. Soc. Trans. 29: 684-688

5. Ashkenazi A (2002) Targeting death and decoy receptors of the tumournecrosis factor superfamily. Nat. Rev. Cancer 2: 420-430

6. Davis RJ (2000) Signal transduction by the JNK group of MAP kinases. Cell 103: 239-252

7. Ichijo H (1999) From receptors to stress-activated MAP kinases. Oncogene 18: $6087-6093$

8. Erhardt P, Schremser EJ and Cooper GM (1999) B-Raf inhibits programmed cell death downstream of cytochrome $c$ release from mitochondria by activating the MEK/Erk pathway. Mol. Cell. Biol. 19: 5308-5315

9. von Gise A, Lorenz P, Wellbrock C, Hemmings B, Berberich-Siebelt F, Rapp UR and Troppmair J (2001) Apoptosis suppression by Raf-1 and MEK1 requires MEK- and phosphatidylinositol 3-kinase-dependent signals. Mol. Cell. Biol. 21: 2324-2336

10. Graves JD, Draves KE, Craxton A, Saklatvala J, Krebs EG and Clark EA (1996) Involvement of stress-activated protein kinase and p38 mitogen-activated protein kinase in mlgM-induced apoptosis of human B lymphocytes. Proc. Natl. Acad. Sci. USA 93: 13814-13818

11. Kinoshita T, Yokota T, Arai K and Miyajima A (1995) Suppression of apoptotic death in hematopoietic cells by signalling through the IL-3/GM-CSF receptors. EMBO J. 14: 266-275

12. Raingeaud J, Gupta S, Rogers JS, Dickens M, Han J, Ulevitch RJ and Davis RJ (1995) Pro-inflammatory cytokines and environmental stress cause p38 mitogen-activated protein kinase activation by dual phosphorylation on tyrosine and threonine. J. Biol. Chem. 270: 7420-7426

13. Xia Z, Dickens M, Raingeaud J, Davis RJ and Greenberg ME (1995) Opposing effects of ERK and JNK-p38 MAP kinases on apoptosis. Science 270: 1326-1331

14. Tamura S, Hanada M, Ohnishi M, Katsura K, Sasaki M and Kobayashi T (2002) Regulation of stress-activated protein kinase signaling pathways by protein phosphatases. Eur. J. Biochem. 269: 1060-1066

15. Willoughby EA, Perkins GR, Collins MK and Whitmarsh AJ (2003) The JNKinteracting protein-1 scaffold protein targets MAPK phosphatase-7 to dephosphorylate JNK. J. Biol. Chem. 278: 10731-10736

16. Merchant JL, lyer GR, Taylor BR, Kitchen JR, Mortensen ER, Wang Z, Flintoft RJ, Michel J and Bassel-Duby R (1996) ZBP-89, a Krüppel-type zinc finger protein, inhibits EGF induction of the gastrin promoter. Mol. Cell. Biol. 16: 6644-6653

17. Bai L, Logsdon $C$ and Merchant JL (2002) Regulation of epithelial cell growth by ZBP-89: potential relevance in pancreatic cancer. Int. J. Gastro. Can. 31: $79-88$

18. Bai $L$ and Merchant JL (2001) ZBP-89 promotes growth arrest through stabilization of p53. Mol. Cell. Biol. 21: 4670-4683

19. Remington MC, Tarle SA, Simon B and Merchant JL (1997) ZBP-89, a Kruppeltype zinc finger protein, inhibits cell proliferation. Biochem. Biophys. Res. Commun. 237: 230-234

20. Takeuchi A, Mishina Y, Miyaishi O, Kojima E, Hasegawa T and Isobe KI (2003) Heterozygosity with respect to Zfp148 causes complete loss of fetal germ cells during mouse embryogenesis. Nat. Genet. 33: 172-176

21. Kharbanda S, Pandey P, Schofield L, Israels S, Roncinske R, Yoshida K, Bharti A, Yuan ZM, Saxena S, Weichselbaum R, Nalin C and Kufe D (1997) Role for $\mathrm{Bcl}-\mathrm{xL}$ as an inhibitor of cytosolic cytochrome $c$ accumulation in DNA damageinduced apoptosis. Proc. Natl. Acad. Sci. USA 94: 6939-6942

22. Kluck RM, Bossy-Wetzel E, Green DR and Newmeyer DD (1997) The release of cytochrome $c$ from mitochondria: a primary site for Bcl- 2 regulation of apoptosis [see comments]. Science 275: 1132-1136
23. Li P, Nijhawan D, Budihardjo I, Srinivasula SM, Ahmad M, Alnemri ES and Wang X (1997) Cytochrome $c$ and dATP-dependent formation of Apaf-1/ caspase-9 complex initiates an apoptotic protease cascade. Cell 91: 479-489

24. Inoshita S, Takeda K, Hatai T, Terada Y, Sano M, Hata J, Umezawa A and Ichijo $\mathrm{H}$ (2002) Phosphorylation and inactivation of myeloid cell leukemia 1 by JNK in response to oxidative stress. J. Biol. Chem. 277: 43730-43734

25. Weber JD, Raben DM, Phillips PJ and Baldassare JJ (1997) Sustained activation of extracellular-signal-regulated kinase 1 (ERK1) is required for the continued expression of cyclin D1 in G1 phase. Biochem. J. 326: 61-68

26. Swank MW and Sweatt JD (2001) Increased histone acetyltransferase and lysine acetyltransferase activity and biphasic activation of the ERK/RSK cascade in insular cortex during novel taste learning. J. Neurosci. 21: 3383-3391

27. Cross TG, Scheel-Toellner D, Henriquez NV, Deacon E, Salmon M and Lord JM (2000) Serine/threonine protein kinases and apoptosis. Exp. Cell Res. 256: 34-41

28. Franklin RA and McCubrey JA (2000) Kinases: positive and negative regulators of apoptosis. Leukemia 14: 2019-2034

29. Bacus SS, Gudkov AV, Lowe M, Lyass L, Yung Y, Komarov AP, Keyomarsi K, Yarden $Y$ and Seger R (2001) Taxol-induced apoptosis depends on MAP kinase pathways (ERK and p38) and is independent of p53. Oncogene 20: $147-155$

30. Kibbe MR, Li J, Nie S, Choi BM, Kovesdi I, Lizonova A, Billiar TR and Tzeng E (2002) Potentiation of nitric oxide-induced apoptosis in p53-/- vascular smooth muscle cells. Am. J. Physiol. Cell Physiol. 282: C625-C634

31. Kharbanda S, Saxena S, Yoshida K, Pandey P, Kaneki M, Wang Q, Cheng K Chen YN, Campbell A, Sudha T, Yuan ZM, Narula J, Weichselbaum R, Nalin C and Kufe D (2000) Translocation of SAPK/JNK to mitochondria and interaction with $\mathrm{Bcl}-\mathrm{x}(\mathrm{L})$ in response to DNA damage. J. Biol. Chem. 275: 322-327

32. Tournier C, Hess P, Yang DD, Xu J, Turner TK, Nimnual A, Bar-Sagi D, Jones SN, Flavell RA and Davis RJ (2000) Requirement of JNK for stress-induced activation of the cytochrome $c$-mediated death pathway. Science 288: 870-874

33. Meriin AB, YaglomJA, Gabai VL, Zon L, Ganiatsas S, Mosser DD and Sherman MY (1999) Protein-damaging stresses activate c-Jun N-terminal kinase via inhibition of its dephosphorylation: a novel pathway controlled by HSP72. Mol. Cell. Biol. 19: 2547-2555

34. Willoughby EA, Perkins GR, Collins MK and Whitmarsh AJ (2003) The JNKinteracting protein-1 scaffold protein targets MAPK phosphatase-7 to dephosphorylate JNK. J. Biol. Chem. 278: 10731-10736

35. Marti F, Krause A, Post NH, Lyddane C, Dupont B, Sadelain M and King PD (2001) Negative-feedback regulation of CD28 costimulation by a novel mitogen-activated protein kinase phosphatase, MKP6. J. Immunol. 166: 197-206

36. Chen YR, Wang X, Templeton D, Davis RJ and Tan TH (1996) The role of cJun $\mathrm{N}$-terminal kinase (JNK) in apoptosis induced by ultraviolet $\mathrm{C}$ and gamma radiation. Duration of JNK activation may determine cell death and proliferation. J. Biol. Chem. 271: 31929-31936

37. Verheij M, Bose R, Lin XH, Yao B, Jarvis WD, Grant S, Birrer MJ, Szabo E, Zon LI, Kyriakis JM, Haimovitz-Friedman A, Fuks Z and Kolesnick RN (1996) Requirement for ceramide-initiated SAPK/JNK signalling in stress-induced apoptosis. Nature 380: 75-79

38. Zanke BW, Boudreau K, Rubie E, Winnett E, Tibbles LA, Zon L, Kyriakis J, Liu FF and Woodgett JR (1996) The stress-activated protein kinase pathway mediates cell death following injury induced by cis-platinum, UV irradiation or heat. Curr. Biol. 6: 606-613

39. Caraglia M, Abbruzzese A, Leardi A, Pepe S, Budillon A, Baldassare G, Selleri C, Lorenzo SD, Fabbrocini A, Giuberti G, Vitale G, Lupoli G, Bianco AR and Tagliaferri $P$ (1999) Interferon-alpha induces apoptosis in human KB cells through a stress-dependent mitogen activated protein kinase pathway that is antagonized by epidermal growth factor. Cell Death Differ. 6: 773-780

40. Lenczowski JM, Dominguez L, Eder AM, King LB, Zacharchuk CM and Ashwell JD (1997) Lack of a role for Jun kinase and AP-1 in Fas-induced apoptosis. Mol. Cell. Biol. 17: 170-181

41. Liu ZG, Hsu H, Goeddel DV and Karin M (1996) Dissection of TNF receptor 1 effector functions: JNK activation is not linked to apoptosis while NF-kappaB activation prevents cell death. Cell 87: $565-576$

42. Theodosiou A and Ashworth A (2002) Differential effects of stress stimuli on a JNK-inactivating phosphatase. Oncogene 21: 2387-2397 
43. Weston CR and Davis RJ (2002) The JNK signal transduction pathway. Curr. Opin. Genet. Dev. 12: 14-21

44. Harkin DP, Bean JM, Miklos D, Song YH, Truong VB, Englert C, Christians FC, Ellisen LW, Maheswaran S, Oliner JD and Haber DA (1999) Induction of GADD45 and JNK/SAPK-dependent apoptosis following inducible expression of BRCA1. Cell 97: 575-586

45. Fornace Jr AJ, Jackman J, Hollander MC, Hoffman-Liebermann B and Liebermann DA (1992) Genotoxic-stress-response genes and growth-arrest genes. gadd, MyD, and other genes induced by treatments eliciting growth arrest. Ann. NY Acad. Sci. 663: 139-153

46. Hasegawa T, Xiao H and Isobe KI (1999) Cloning of a GADD34-like gene that interacts with the zinc-finger transcription factor which binds to the p21 WAF promoter. Biochem. Biophys. Res. Commun. 256: 249-254

47. Mansour SJ, Matten WT, Hermann AS, Candia JM, Rong S, Fukasawa K Vande Woude GF and Ahn NG (1994) Transformation of mammalian cells by constitutively active MAP kinase kinase. Science 265: 966-970

48. Xia Z, Dickens M, Raingeaud J, Davis RJ and Greenberg ME (1995) Opposing effects of ERK and JNK-p38 MAP kinases on apoptosis. Science 270: 1326-1331

49. Galve-Roperh I, Sanchez C, Cortes ML, del Pulgar TG, Izquierdo M and Guzman M (2000) Anti-tumoral action of cannabinoids: involvement of sustained ceramide accumulation and extracellular signal-regulated kinase activation. Nat. Med. 6: 313-319

50. Pumiglia KM and Decker SJ (1997) Cell cycle arrest mediated by the MEK/mitogen-activated protein kinase pathway. Proc. Natl. Acad. Sci. USA 94 448-452

51. Ryan KM, Ernst MK, Rice NR and Vousden KH (2000) Role of NF-kappaB in p53-mediated programmed cell death. Nature 404: 892-897

52. Stanciu M, Wang Y, Kentor R, Burke N, Watkins S, Kress G, Reynolds I, Klann E, Angiolieri MR, Johnson JW and DeFranco DB (2000) Persistent activation of ERK contributes to glutamate-induced oxidative toxicity in a neuronal cell line and primary cortical neuron cultures. J. Biol. Chem. 275: 12200-12206

53. Yan Y, Haas JP, Kim M, Sgagias MK and Cowan KH (2002) BRCA1-induced apoptosis involves inactivation of ERK1/2 activities. J. Biol. Chem. 24: 24

54. Giaccia AJ and Kastan MB (1998) The complexity of p53 modulation: emerging patterns from divergent signals. Genes Dev. 12: 2973-2983

55. Lowe SW, Ruley HE, Jacks T and Housman DE (1993) p53-dependen apoptosis modulates the cytotoxicity of anticancer agents. Cell 74: 957-967

56. Miyashita T and Reed JC (1995) Tumor suppressor p53 is a direct transcriptional activator of the human bax gene. Cell 80: 293-299

57. Oltvai ZN, Milliman CL and Korsmeyer SJ (1993) Bcl-2 heterodimerizes in vivo with a conserved homolog, Bax, that accelerates programmed cell death. Cell 74: 609-619
58. Deng X, Xiao L, Lang W, Gao F, Ruvolo P and May Jr MS (2001) Novel role for JNK as a stress-activated Bcl2 kinase. J. Biol. Chem. 276: 23681-23688

59. Fan M, Goodwin M, Vu T, Brantley-Finley C, Gaarde WA and Chambers TC (2000) Vinblastine-induced phosphorylation of $\mathrm{Bcl}-2$ and $\mathrm{Bcl}-\mathrm{XL}$ is mediated by JNK and occurs in parallel with inactivation of the Raf-1/MEK/ERK cascade. J. Biol. Chem. 275: 29980-29985

60. Maundrell K, Antonsson B, Magnenat E, Camps M, Muda M, Chabert C, Gillieron C, Boschert U, Vial-Knecht E, Martinou JC and Arkinstall S (1997) Bcl2 undergoes phosphorylation by c-Jun $\mathrm{N}$-terminal kinase/stress-activated protein kinases in the presence of the constitutively active GTP-binding protein Rac1. J. Biol. Chem. 272: 25238-25242

61. Nishina H, Radvanyi L, Raju K, Sasaki T, Kozieradzki I and Penninger JM (1998) Impaired TCR-mediated apoptosis and Bcl-XL expression in T cells lacking the stress kinase activator SEK1/MKK4. J. Immunol. 161: 3416-3420

62. Yamamoto K, Ichijo H and Korsmeyer SJ (1999) BCL-2 is phosphorylated and inactivated by an ASK1/Jun N-terminal protein kinase pathway normally activated at G(2)/M. Mol. Cell. Biol. 19: 8469-8478

63. Ando T, Umezawa A, Suzuki A, Okita H, Sano M, Hiraoka Y, Aiso S, Saruta T and Hata J (1998) EAT/mcl-1, a member of the bcl-2 related genes, confers resistance to apoptosis induced by cis-diammine dichloroplatinum (II) via a p53independent pathway. Jpn. J. Cancer Res. 89: 1326-1333

64. Croxton R, Ma Y, Song L, Haura EB and Cress WD (2002) Direct repression of the Mcl-1 promoter by E2F1. Oncogene 21: 1359-1369

65. Lin MT, Juan CY, Chang KJ, Chen WJ and Kuo ML (2001) IL-6 inhibits apoptosis and retains oxidative DNA lesions in human gastric cancer AGS cells through up-regulation of anti-apoptotic gene mcl-1. Carcinogenesis 22: 1947-1953

66. Strasberg Rieber, Zangemeister-Wittke $U$ and Rieber M (2001) p53-Independent induction of apoptosis in human melanoma cells by a bcl-2/bcl-xL bispecific antisense oligonucleotide. Clin. Cancer Res. 7: 1446-1451

67. Bai $L$ and Merchant JL (2000) Transcription factor ZBP-89 cooperates with histone acetyltransferase p300 during butyrate activation of p21waf1 transcription in human cells. J. Biol. Chem. 275: 30725-30733

68. Harrington AW, Kim JY and Yoon SO (2002) Activation of Rac GTPase by p75 is necessary for $\mathrm{C}$-jun $\mathrm{N}$-terminal kinase-mediated apoptosis. J. Neurosci. 22: $156-166$

69. Liu X, Kim CN, Yang J, Jemmerson R and Wang X (1996) Induction of apoptotic program in cell-free extracts: requirement for dATP and cytochrome c. Cell 86: $147-157$

70. Elbashir SM, Harborth J, Lendeckel W, Yalcin A, Weber K and Tuschl T (2001) Duplexes of 21-nucleotide RNAs mediate RNA interference in cultured mammalian cells. Nature 411: 494-498 